\title{
KELONG-KELONG DAERAH MASSENRENGPULU KABUPATEN ENREKANG SEBAGAI SALAH SATU MUATAN PENDIDIKAN KARAKTER Maryam Ngende
}

\begin{abstract}
ABSTRAK
Penelitian ini bertujuan mendeskripsikan (1) karakter masyarakat Massenrengpulu dalam syair-syair lagu dari daerah Massenrengpulu Kabupaten Enrekang. (2) Penggunaan Stilistika dalam syair-syair lagu dari daerah Massenrengpulu Kabupaten Enrekang. Jenis penelitian ini deskriptif. Data penelitian ini terdiri atas primer yakni data yang diperoleh langsung dari objek penelitian tentang syair lagu dari Daerah Massenrengpulu Kabupaten Enrekang. Data sekunder didapatkan dari sumber yang dapat mendukung penelitian antara lain dari literature-literatur, internet, serta penelitian sebelumnya mengenai studi semiotic terhadap syair lagu. Teknik pengumpulan data penelitian ini adalah dokumentasi, studi pustaka, dan analisis teks (teknik baca). Analisis data yang digunakan dalam penelitian ini adalah analisis kualitatif. Hasil penelitian menunjukkan (1) karakter masyarakat Massenerngpulu dalam syair-syair lagu Daerah Massenrengpulu Kabupaten Enrekang dikenal sebagai masyarakat yang menjunjung tinggi nilai moral dalam kehidupan. Pada dimensi nilai moral ini ditemukan nilai-nilai yang relevan dengan moralitas dalam kehidupan pribadi manusia, nilai-nilai tersebut adalah nilai kesederhaan, kejujuran, serta nilai tanggung jawab. (2) Syair-syair lagu daerah Massenrengpulu Kabupaten Enrekang diciptakan oleh penyair dengan menggunakan gaya tersendiri, seperti penyair menggunakan gaya hiperbol, penggunaan diksi, metafor, citraan, nonsense, dan personifikasi. Gaya penulisan lagu Massenrengpulu rata-rata mengacu pada pemaknaan masyarakat, kondisi kehidupan, serta latar alam budaya masyarakat Massenrengpulu.
\end{abstract}

Kata kunci: Kelong daerah, muatan, pendidikan karakter

\section{ABSTRAC}

This research aimed to describe (1) the character of Massenrengpulu Community in lyrics of Massenrengpulu Traditional Songs of Enrekang Regency. The secondary data gained from the research supporting such as: literature, internet, and the research about semiotic of lyrics in advance. The technique in collecting data used documentation, library study, and text analyzing. The analysis that used in this research was research was qualitative analysis. Research findings indicated that (1) the character of Massenrengpulu community in lyrics of Massenrengpulu Traditional Songs of Enrekang Regency known as the community who uphold the moral value in their life. In moral dimension was found the values that same as the personal value of Massenrengpulu Traditional Songs created by the writer by using self-style, likes: using hyperbola style, diction, metaphor, nonsense, and personification. Writing style Massenrengpulu Traditional Songs usedlife condition, and culture background of Massenrengpulu community.

Key word: Traditional songs, conten, character 


\section{PENDAHULUAN}

Manusia dan kebudayaan adalah dua hal yang tidak dapat dipisahkan. Keduanya saling memengaruhi dalam proses hidup dan kehidupan manusia, baik dalam tataran sosial-kemasyarakatan, tataran sosialpolitik, maupun tataran sosial-ekonomi. Naisbit (dalam Ambo Enre,1991: 1-2), mengungkapkan bahwa keperluan akan pengungkapan, penerapan, dan pemantapan nilai-nilai luhur budaya bangsa pada akhir-akhir ini, terasa kian mendesak, tidak hanya karena menurut kenyataan, ia semakin tercecer ke belakang dan sering terlupakan, melainkan juga karena munculnya gaya hidup global yang semakin meluas pada penghujung abad ke-20 ini.

Kesusastraan Massenrengpulu khususnya kelong Massenrengpulu, memiliki sifat-sifat seperti yang telah diuraikan di atas, terlebih dalam kaitannya dengan tata-nilai moralreligius kehidupan masyarakat. Kesusastraan Massenrengpulu pada saat ini, dapat dikatakan tengah mengalami satu fase kemunduran. Kebudayaan ini diharapkan dapat melestarikan nilai-nilai yang terdapat di dalam kelong.

Lagu dan syair

Massenrengpulu merupakan salah satu wujud dari kebudayaan agung masyarakat Massenrengpulu. Faktor keterbatasan pemahaman tentang syair dan lagu inilah yang menjadikan syairsyair itu kurang bermakna.

Sudah menjadi tanggung jawab bagi setiap masyarakat dalam menjaga dan melestarikan budaya kesenian tersebut. Musik Bambu misalnya merupakan alat musik tradisional Suku Massenrengpulu Kabupaten Enrekang Sulawesi Selatan, yang terancam punah. Salah satu lagu Massenrengpulu yang sering dimainkan adalah lagu Suruganna Bambapuang atau surga dari Gunung Bambapuang.

Lirik lagu Massenrengpulu merupakan karya budaya lokal yang mengandung muatan lokal kedaerahan, terutama sebagai cerminan bagi masyarakat Massenrengpulu. Lagulagu tersebut menjadi agen dalam menanamkan karakter kepada generasi pelanjut masyarakat. Dengan demikian, melalui lagu-lagu masyarakat luas akan memahami identitas dan karakter masyarakat Massenrengpulu.

Selain penanaman nilai karakter dalam lagu Massenrengpulu, juga ditampilkan stilistika atau gaya penciptaan lagu itu. Hal ini sejalan dengan pendapat Sudjiman (1993:18 jika wacana bahasa dapat dikaji secara linguistik, maka tidak mustahil menerapkan pendekatan linguistik pada wacana sastra.

Stilistika merupakan cabang linguistik yang menelaah pemakaian bahasa dan gaya bahasa termasuk efek yang ditimbulkan oleh cara penggunaan bahasa dalam karya sastra. Keindahan sebuah karya sastra sebagian besar disebabkan oleh kemampuan penulis bahasanya menimbulkan kekuatan bahasa dan keindahannya (Semi, 1993:56).

Kajian nilai dan karakter serta stilistika itu perlu dilakukan, bukan hanya dalam rangka memberikan sumbangan bermakna terhadap kritik 
sastra, melainkan juga dalam rangka memberi deskripsi yang bermakna terhadap karya sastra di Sulawesi Selatan khusus pada lagu Massenrengpulu yang mendeskripsikan kajian stilistika dalam lirik lagu-lagu Massenrengpulu.

\section{TINJAUAN PUSTAKA}

\section{Deskripsi Suku Massenrengpulu}

Penduduk asli di gunugn Bambapuang ini tersebar ke Timur daerah Duri, ke Selatan daerah Maiwa Sidenreng, ke Barat daerah Pinrang dan Polmas, ke Utara daerah Tanah Toraja bertemu dengan penduduk asli disana yang naik perahu yang melalui sungai Saddang. Penduduk asli Bambapuang dan kampung Tinggallung di sebelah baratnya. Dan penduduk kampung Papi, Kotu, Kaluppini, Bisang, Leorang, Tanete Carruk dan kampungkampung di daerah Maiwa, Duri, Pinrang, Binuang, Tanah Toraja bagian selatan.

\section{Lagu}

\section{a. Pengertian Lagu}

Elong adalah suatu karya sastra orang Enrekang yang sudah memasyarakat ditengah masyarakat sejak zaman dahulu. Unutk memahami makna elong, diperlukan pengetahuan khusus, karena memahami makna elong mempunyai sifat-sifat tertentu bagaimana halnya pengenalan sifatsifat pada puisi.

Cara Pakkelong (Pengarang atau pembawa elong) melukiskan pikiran dan perasaan antara lain :

1) Pernyataan langsung Pakkelong menyatakan pikiran dan perasaan secara langsung dengan mempergunakan bahasa yang mudah dimengerti oleh pendengarnya.

2) Pengiasan

Pakkelong melukiskan dan perasaan tidak dengan terus terang, melainkan dengan terkias.

3) Asosiasi Bunyi Ucapan.

4) Pakkelong menyampaikan ucapan dengan melalui cara dan pengertian yang samarsamar, atau dengan kata terkias.

Alwi dkk. (2007:624) terdapat pengertian lagu yang berarti: (1) Ragam suara yang berirama (dalam bercakap, membaca, dan sebagainya), (2) Menyanyi, nyanyian, (3) Ragam menyanyi (musik, gamelang, dsb.), dan (4) Tingkah laku, cara, lagak. Sedangkan pengertian lirik adalah: (1) Karya sastra (puisi) yang berisi curahan perasaan pribadi, dan (2) Susunan kata sebuah nyanyian. Adapun pengertian popular adalah: (1) sekenal dan disukai orang banyak (umum) lagu-lagu, (2) sesuai dengan kebutuhan masyarakat pada umumnya; mudah dipahami orang banyak, dan (3) disukai dan dikagumi orang banyak.

\section{b. Unsur-Unsur dalam Syair Lagu}

Bahasa yang digunakan dalam karya sastra harus dibedakan dengan bahasa yang digunakan seharihari, apa lagi dengan bahasa ilmiah. Bahasa sastra penuh ambiguitas dan penuh ekspresif, ini disebabkan bahasa sastra cendrung untuk mempengaruhi, membujuk, dan pada akhirnya mengubah sikaf pembacanya (Wellek dan Warren, 2003:19).

Orkestrasi bunyi yang indah disebut sebagai eufoni, berupa perulangan bunyi vocal $(a, i, u, e, o)$. Ini digunakan untuk menunjukkan suasana senang dan bahagia. Sementara bunyi yang parau diebut sebagai kokofoni 
biasanya berupa kombinasi bunyi $\mathrm{k}, \mathrm{p}, \mathrm{t}, \mathrm{s}$. bunyi jenis ini dapat dapat menunjukkan suasana kesakitan, tidak menyenangkan, kekacauan, dan mistis (Pradopo, 2009:32).

Menurut Awe (2003:31), pembicaraan tentang kata pada puisi berarti berbicara mengenai arti kata dan efek yang ditimbulkan melalui. Diksi, kosakata, denotasi dan konotasi, bahasa kias, dan sarana retorika.

\section{c. Unsur Ekstirinsik Lagu}

Nurgiantoro

(2009:77)

Faktor ekstrinsik adalah segala faktor luar yang melatarbelakangi penciptaan karya sastra. Ia merupakan milik subjektif pengarang yang bisa berupa kondisi sosial, motivasi, tendensi yang mendorong dan memengaruhi kepengarangan seseorang.

\section{Pengertian Nilai}

Nilai adalah suatu perangkat ataupun perasaan yang diyakini sebagai identitas yang memberikan corak khusus kepada pola pemikiran, perasaan, keterkaitan, dan prilaku. Dalam Kamus Besar Bahasa Indonesia (Ali, dkk., 1996:690) dikatakan bahwa nilai adalah sifat-sifat atau hal-hal yang penting dan berguna bagai kemanisaan.

\section{Hakikat Pendidikan}

Langeveld dalam Tumpu (1997: 16) mengemukakan bahwa pendidikan adalah pengaruh yang diberikan oleh orang dewasa yang bertanggung jawab kepada anak-anak yang belum dewasa untuk mencapai kedewasaannya. Tujuannya adalah untuk membina kepribadian dan pengembangan kemampuan manusia Indonesia baik jasmani maupun rohani yang berlangsung seumur hidup. Selanjutnya, Napitupulu (dalam Tumpu, 1997:16) berpendapat bahwa pendidikan sebagai kegiatan yang dilahirkan secara sengaja, teratur, dan berencana dengan tujuan mengubah tingkah laku ke arah yang diinginkan.

Ali (1957:149) mengartikan pendidikan sebagai segala usaha dan pembuatan dan generasi tua untuk mengalihkan pengalaman, pengetahuan dalam keterampilan kepada generasi muda untuk melangsungkan fungsi hidup dengan baik. Pendidikan oleh orang tua memberikan contoh yang baik dalam sikap hidupnya, berbagai pengetahuan dan nasihat-nasihat, guru melaksanakan tugasnya dengan baik.

\section{Aksiologi (Nilai) Pendidikan}

Manusia dapat mengomunikasikan kebudayaan dan warisan intelektualnya pada generasi yang akan datang serta memberikan inspirasi cita-cita hidupnya. Dengan demikian, secara aksiologi pendidikan, maka yang dapat dikaji dalam sebuah tulisan termasuk dalam sebuah karya sastra.

\section{Stilistika}

a. Pengertian Stilistika

Stilistika berasal dari Bahasa Inggris yaitu style yang berarti gaya dan dari bahasa serapan linguistik yang berarti tata bahasa. Stilistika menurut kamus Bahasa Indonesia (KKBI, 2007;32), yaitu ilmu kebahasaan yang mempelajari gaya bahasa. Stilistika merupakan ilmu gabungan antara linguistik dengan sastra. Menurut Rene Wellek dan Austin Warren, stilistika perhatian utamanya adalah kontras sistem bahasa pada zamanya (Aminuddin, 2001:22).

Makna denotasi bersifat langsung, yaitu makna khusus yang terdapat dalam sebuah tanda, dan pada intinya dapat disebut gambaran sebuah petanda (Piliang, 2003:261). Misal. kata kucing dapat didefenisikan sebagai penggambaran hewan berkaki empat, berbulu dan berkumis. 
Konvensi bahasa dalam puisi meliputi diksi baik berupa inguis dan ingui, maupun struktur sintasksisnya. Di dalam kata-kata puisi/syair keberadaan ingui dan lambing diperlukan permaknaan lebih lanjut karena pengarang sering menggunakan bahasa kiasan. Hal ini terjadi karena pengarang ingin menciptakan efek-efek tertentu bagi puisinya (Awe, 2003:49).

Variasi penggunaan bahasa dalam karya sastra menimbulkan ragam atau gaya bahasa tersendiri gaya bahasa itu merupakan pusat kajian disiplin stilistika. Stilistika mengkaji suatu wacana sastra dengan orientasi linguistik. Stilistika mengkaji cara sastrawan memanfaatkan unsur yang terdapat dalam bahasa dan efek apa yang ditimbulkannya (Sudjiman, 1993:18).

b. Ketidaklangsungan ekspresi sebagai bentuk gaya (stilistika)

Bahasa itu merupakan sistem ketandaan yang berdasarkan atau ditentukan oleh konvensi (perjanjian) masyarakat. Meskipun demikian, ketika bahasa digunakan dalam karya sastra, bahasa disesuaikan dengan aturan dalam sastra.

Macam-macam ucapan kiasan merupakan bentuk pengungkapan tidak langsung. Dikatakan "A", dimaksudkan "B". Tentu saja ini tidak bearti bahwa semua objek kongret dan pelukisan selalu mempunyai arti lain dari pada arti harfiah, tetapi biasanya arti itu tunduk kepada tema pokok sajak yang bersangkutan (Luxemburg 1984:191).

c. Jenis Gaya Bahasa

Penggantian arti dalam puisi berupa kata-kata kiasan dengan mengantikan arti suatu hal dengan arti yang lain. Penggantian arti dapat dikategorikan atas: 1) perbandingan, 2) metafora, 3) Simile, 4)litotes, 5) alegoril, pemanusiaan, 7) personifikas, 8) penyebutan sebagian, 9) sinekdoke, 10) sinekdoke pras pro toto, 11) sinekdoke tetem to parte, 12) metonimia, 13) penyimpangan arti, 14) ambiguitas, 15) kontradiksi, 16) antithesis, 17) paradox, 18) Hiperbola, 19) ironi, 20) Eufemisme, 21) nonsense, 22) penciptaan arti, dan 23) private symbol.

\section{Karakteristik masyarkat dalam lagu sebagai bagian dari karya sastra}

Untuk mengenal masyarakat itu, bagaimana kebiasaannya, betapa karak-

ternya, tingkah lakunya, dapat dilihat lewat alat-alat yang dipergunakan pengarang

seperti bahasa, sikap, kebiasaan, penggambaran tubuhnya, perbincangan pelaku

lain tentang dirinya dan sebagainya (Jene, 1998:13).

Sumardjo

mengatakan bahwa untuk mengenal watak seseorang dapat diteliti, (1) apa yang dikatakan, (2) apa yang dilakukannnya, (3) bagaimana siakapnya dalam menghadapi persoalan, dan (4) bagaimana penilaian tokoh lain diatas dirinya. Minderop (2005:2) menyatakan bahwa karakter atau watak adalah sifat-sifat khas masyarakat yang diceritakan tentang kualitas nalar, sikap, tinggkah laku pribadi, jiwa yang dibedakan dengan masyarakat lain dalam sebuah karya.

Menurut Suroto (1989:47), penokohan atau perwatakan adalah bagaimana

Pengarang menampilkan masyarakat tersebut. Ini berarti ada dua hal yang sangat

penting yaitu hubungan dengan teknik penyampaian dan berhubungan dengan watak atau kepribadian masyarkat yang tampil. 


\section{METODE}

\section{Metode Penelitian}

Dalam bab ini penulis menjabarkan metodologi yang akan digunakan dalam penelitian ini, untuk mendapatkan data yang berkaitan dengan penelitian yang penulis teliti. Penulis akan menjelaskan metode penelitian, pendekatan penelitian, objek penelitian, metode pengumpulan data, dan metode analisis data.

\section{Jenis Penelitian}

Penelitian ini dilakukan dengan menggunakan metode analisis teks dengan pendekatan semiotika. Metode semiotika bersifat kualitatifinterpretatif.

\section{Objek Penelitian}

Pada penelitian ini, objek yang akan diteliti adalah nilai karakter dalam

syair lagu dari daerah Massenrengpulu Kabupaten Enrekang. Subjek penelitian ini

didapatkan dengan menulis kembali syair yang terdapat pada lagu untuk kemudian digunakan sebagai data penelitian.

\section{Data dan Sumber Data}

1. Data Primer

Data primer adalah data yang diperoleh langsung dari objek penelitian. Dalam penelitian ini peneliti menggunakan data primer berupa syair lagu dari daerah Massenrengpulu Kabupaten Enrekang.

2. Data Sekunder

Data sekunder didapatkan dari sumber yang dapat mendukung penelitian antara lain dari literaturliteratur, internet, serta penelitian sebelumnya mengenai studi semiotik terhadap syair lagu. Peneliti juga menggunakan pustaka dalam usaha memeroleh informasi tentang studi semiotika pada teks berupa syair dan lagu.

5. Teknik Pengumpulan Data

1. Dokumentasi

2. Studi Pustaka

3. Analisis Teks

\section{Teknik Analisis Data}

Analisis data yang digunakan dalam penelitian ini adalah deskriptif kualitatif. Metode kualitatif digunakan untuk mendapatkan rincian data yang mengandung makna. Makna adalah data yang sebenarnya, suatu nilai dibalik data yang tampak. Oleh karena itu, dalam penelitian kualitatif tidak menekankan pada generalisasi, tetapi lebih menekankan pada makna (Sugiyono, 2005: 201).

\section{Valliditas Data}

Validitas dalam penelitian ini berupa derajat ketepatan antara data yang

terjadi pada objek penelitian dengan hasil yang diperoleh oleh peneliti. Penelitian dapat diuji keabsahannya berdasarkan hal yang terjadi pada objek sesuai dengan hasil yang dilaporkan. Penelitian ini menggunakan data analisis lagu daerah Massenrengpulu Kabupaten Enrekang dan menyesuaikan berdasarkan tanda-tanda atau simbol-simbol yang terdapat di dalamnya bekerja sebagai pembentuk makna pesan yang sebenarnya.

\section{HASIL PENELITIAN DAN PEMBAHASAN}

1. Karakteristik Masyarakat Massenrengpulu dalam SyairSyair Lagu Daerah Massenrengpulu Kabupaten Enrekang 
Lagu-lagu Massenrengpulu antara lain Suruganna Bambapuang, Tuntung Kaloko, Candingku, dan Salu Dewata adalah karya turun temurun masyarakatnya. Syair lagu ini merupakan karakter dari masyarakat akan kecintaannya terhadap ciptaan Tuhan, kasih sayang, kebersamaan, dan sikap yang mencerminkan karakter masyarakat itu sendiri.

Untuk memertegas tentang nilai-nilai karakter masyarakat dalam syair lagu Massenrengpulu, maka akan dijelaskan beberapa dimensi nilai moral yang terdapat pada syair lagu tersebut, yakni:

\section{Karakter}

Massenrengpulu

masyarakat yang berperilaku moral dengan orang lain (nilainilai moral sosial)

Nilai moral dalam kehidupan manusia dengan orang lain (nilai-nilai moral sosial) yang ditemukan dalam lagu-lagu Massenrengpulu tampak pada kutipan berikut ini.

Teks pertama

Tuntun Kaloko' umboroko nena bongi (Burung Hantu di mana engkau tadi malam ?)

Denna jio randan salu kupangbongiananni

toratungku (Saya berada di pinggir kali bermalam dengan tamu Saya)

\section{(Sumber: Lagu Tuntun Kaloko)}

Lirik lagu tersebut mencerminkan salah satu perilaku sosial masyarakat Massenrengpulu yang digambarkan melalui asosiasi judul lagu Tuntun Kaloko' burung Hantu. Salah satu lirik lagu ini adalah Denna jio randan salu kupangbongiananni toratungku. Lirik ini menggambarkan perilaku sosial masyarakat, terutama dalam menghargai sesama manusia.

Teks kedua

Tuntun Kaloko' benna
sangpulo tallomu ('Burung Hantu berikan saya sepuluh telurmu)

Benna' dikka'na ridomu na kunasuanni toratungku' (berikan saya kasihan berasmu untuk saya masakkan tamu saya)

(Sumber: Lagu Tuntun Kaloko')

Lirik lagu tersebut megandung pesan agar manusia selalu ingat akan keberadaannya dan selalu saling membantu dalam aktivitas kehidupan. Dalam artian, manusia diharapkan tidak menonjolkan sifat-sifat yang dapat menurunkan derajat kemanusiaannya, seperti sombong, angkuh, kikir, dan dengki.

3. Karakter

masyarakat Massenrengpulu sebagai masyarakat yang berperilaku moral dalam hubungannya dengan tuhan.

Data yang menggambarkan nilai moral kehidupan manusia dalam hubungannya dengan Tuhan tampak pada lirik lagu berikut ini.

Dapo dewata buntu padidi (Dapur Dewa ada di gunung Padidi)

Salu dewata buntu ampang (Sungai Dewa di gunung Ampang)

Wainna malinnong na

mapaccing (Airnya jernih dan bersih)

Napake pariu tau

buda(Dipakai bersawah orang banyak)

Lo'ko' dewata jao

tumonga'(Goa Dewa di atas Tumonga)

Nanei messerang kalumpini

(Tempat bersarang burung Walet)

Benteng pertahanan jao

lempang (Benteng pertahanan di atas Lempang) 
Nanei bertahan tojolojolota'(Tempat bertahan orang zaman dahulu)

\section{(Sumber: Lagu Salu Dewata)}

Lirik lagu tersebut mencerminkan kebesaran Tuhan akan ciptaan-Nya bahwa Bambapuang digambarkan layaknya surga yang anginnya selalu berhembus untuk dijadikan semangat atau sebagai anugerah dari Tuhan. Dengan demikian makna/pesan yang terkandung dalam kelong di atas adalah manusia senantiasa percaya akan kekuasaan Tuhan.

4. Karakteristik masyarakat yang menjunjung tinggi nilai moral dalam kehidupan pribadi manusia (nilai-nilai moral individualisme)

a. Karakteristik Masyarakat yang Menjunjung Tinggi Nilai Kesabaran

Syair lagu Massenrengpulu memiliki makna diam, sabar, dan ingat kepada Tuhan, dan memiliki makna, lebih baik manusia berdiam melakukan zikir Tuhan daripada banyak berbicara namun tanpa arah yang jelas. Data yang menggambarkan kepasrahan masyarakat Massenrengpulu tercermin pada lirik lagu berikut ini.

$O \quad$ o..O candingku annamu kamma' bangra (oh..Pacarku mengapa engkau diam saja) Cukku' batang menggiling de'enraka sussai atimmu (Tunduk membalik seluruh badan, adakah yang yang menyusahkan hatimu)

(Sumber: Lagu Candingku)

b. karakteristik masyarakat yang menjunjung tinggi nilai kepasrahan kepada tuhan (berserah diri)
Kepasrahan kepada Tuhan merupakan salah satu sikap hidup orang Massenrengpulu sebagai ungkapan terima kasih kepada Tuhan yang Maha pemurah. Dengan prinsip hidup ini, masyarakat tidak mempunyai sifat serakah atau iri hati.

c. Masyarakat Massenrengpulu menjunjung tinggi nilai kejujuran dalam hidup

Karakteristik masyarakat Massenrengpulu adalah menjunjung tinggi nilai kejujuran tampak pada lirik lagu berikut ini.

Anggi mangimpuru masa'ku pasusikomu....

('Jangan cemburu, tidak mungkin saya menghianatimu')

(Sumber: Lagu Candingku)

\section{Penggunaan Stilistika dalam Syair-Syair lagu Daerah Massenrengpulu}

1. Penggunaan Gaya Bahasa Hiperbola

Dalam lagu Massenrengpulu, ditemukan penggunaan gaya bahasa yang bersifat melebih-lebihkan (hiperbola), seperti berikut ini.

Ampang')

... ('Sungai Dewa di gunung

Wainna malinnong na mapaccing (Airnya jernih dan bersih)

Napake pariu tau buda (Dipakai bersawah orang banyak )

(Sumber: Lagu Salu Dewata)

2. Gaya Kata (Diksi)

Diksi dapat dikatakan sebagai pilihan kata yang dilakukan oleh pengarang dalam karyanya guna menciptakan efek makna estetik tertentu. Untuk itu, pengarang tidak jarang menggunakan kata konotasi di samping kata denotasi dalam penciptaan sebuah karya. 
3. Nonsense

$O$ o..O candingku annamu kamma' bangra (oh..Pacarku mengapa engkau diam saja) Cukku' batang menggiling de'enraka sussai atimmu (Tunduk membalik seluruh badan, adakah yang yang menyusahkan hatimu).

$O$ o..o candingku pawwanna capakomu (O o..o pacarku beritahu saya, kamu kenapa)

Gaja' kekamma' bangra pangnganna padik ati (Tidak baik kalau hanya diam, menyimpan sakit hati)

4. Citraan

(Sumber: Lagu Candingku)

Wujud citraan yang ditemukan dalam lagu Massenrengpulu tercermin pada lirik berikut ini.

Wainna salu dewata ...(Airnya sungai Dewa)

Makkeguna lako tau (Berguna kepada masyarakat)

5. Metafora

Lirik lagu Massenrengpulu juga menggunakan gaya bahasa metafora yang dapat dilihat pada uraian berikut ini.

Ceppagann ri Lellua (ayam jago dari Lellua)

Sa'pangna ri mendatte ....(ayam jago dari Mendatte)

Pada lirik lagu tersebut terdapat penggunaan gaya bahasa metafora. Hal ini terdapat pada kata ceppaganna pada lirik Ceppaganna ri Lellua. Kata ceppaganna merupakan bentuk asosiasi dan perbandingan antara ayam jago dengan masyarakat Massenrengpulu yang religious sehingga perilaku ini diprediksi membawanya ke alam kebaikan, yakni surga.

6. Personifikasi ...murbei mallun-mallun

(murbey melambai-lambai

(Sumber: Lagu Salu Dewata)

Penggunaan gaya bahasa personifikasi sesuai dengan lagu tersebut tampak pada larik Murbei mallun-mallun "Murbey melambailambai". Murbey dalam lagu tersebut diibaratkan sebagai makhluk bernyawa yang dapat bergerak dan bergoyang.

\section{SIMPULAN DAN SARAN}

\section{Simpulan}

Setelah peneliti mengadakan penelitian dengan pembahasan disimpulkan sebagai berikut :

1. Nilai ekstrinsik yang terdapat pada kelong Massenrengpulu a) nilainilai moral sosial, b) karakter masyarakat Massenrengpulu Kabupaten Enrekang sebagai masyarakat yang berperilaku moral dalam hubungannya dengan Tuhan, c) karakter masyarakat yang menjunjung tinggi nilai moral dalam kehidupan pribadi manusia (nilai-nilai moral individualisme),

2. Stilistika dalam lirik kelong Massenrengpulu.

Stilistika dalam syair lagu Massenrengpulu adalah: a) Gaya bahasa hiperbola, b) gaya kata (Diksi), c) nonsense, d) citraan, e) metafora, f) personifikasi

\section{Saran}

Berdasarkan penelitian dan pembahasan yang dilakukan, maka peneliti ingin menyampaikan beberapa saran yaitu :

1. Bagi para pencipta lagu, hendaknya menciptakan sebuah lagu tidak hanya bersifat sebagai hiburan dan mengejar keuntungan saja, melainkan memberikan makna 
2. Bagi masyarakat sebagai penikmat musik dan lagu seharusnya mulai cerdas serta kritis untuk memilih lagu-lagu yang memiliki kualitas 3. dalam syair lagunya.

\section{DAFTAR PUSTAKA}

Ali, Lukman. 1995. Kamus Besar

Bahasa Indonesia. Jakarta: Depdiukbud-Balai Pustaka.

Alwi, Hasan. 2007. Kamus Besar Bahasa Indonesia. Jakarta: Balai Pustaka.

Aminuddin. 2001. Semantik: Pengantar Studi Tentang Makna. Malang: Sinar Baru Alegresindo.

Awe, Mokoo. 2003. Fals: Nyanyian di Tengah Kegelapan. Yogyakarta: Ombak.

Jene, Bunga. 1998. Analisis Komplik Tokoh Utama Novel di Bawah Lindungan Ka'bah dengan Tenggelamnya Kapal Van Der Wijck. Skripsi.tidak diterbitkan. Ujung Pandang: IKIP UP.

Luxemburg, Jan van. 1984. Pengantar Ilmu Sastra. Diterjemahkan oleh Dick Hartoko. Jakarta: Gramedia.

Moeliono, Anton. M. 1989. Kembara Bahasa. Jakarta: PT. Gramedia.

Nurgiyantoro, Burhan. 2000. Teori Pengkajian Fiksi.
Yogyakarta: Gajah Mada University Press.

Piliang, Yasraf Amir. 2003. Hipersemiotika: Tafsir Culturalal Studies Atas Matinya Makna. Yogyakarta dan Bandung: Jalasutra.

Pradopo, Djoko Rahmat. 2009. Pengkajian Puisi. Yogyakarta: Gadjah Mada Universty Press.

Sugiyono, 2005. Metode Penelitian Kualitatif. Bandung: Alfabeta.

Tarigan, Henry Guntur. 1985. Pengajaran Gaya Bahasa. Bandung: Angkasa.

Tumpu, Sahabuddin. 1997. Pilsafat Pendidikan. Diktat Mahasiswa Program S2 Universitas Negeri Makassar.

Wellek, Rene dan Warren, Austin. 1989. Teori Kesusastraan. Diterjemahkan oleh Melani Budianta. Jakarta: Gramedia. 